\title{
The Effect of Three Different Applications on Rocuronium Injection Pain: A Double Blinded, Randomized Clinical Study \\ Z Arslan ${ }^{1}$, ME Naldan ${ }^{1}$, F Karakoc ${ }^{1}$, M Aktaş ${ }^{1}$, S Celik $^{2}$
}

\begin{abstract}
Background: Some agents such as rocuronium and propofol induce severe and noxious pain when administered intravenously during anesthesia induction. This causes to additional stress for the patient who is already stressful due to operation. The purpose of our study was to compare the effects of remifentanyl with two different administration methods and lidocaine on rocuronium injection pain.
\end{abstract}

Methods: This prospective, double blind, randomized study is designed with 120 patients aged between 17 and 70 years old, American Society of Anesthesiologists (ASA) physical status I-II, undergoing different elective surgery types that require muscle relaxation. Patients were randomly distributed to 3 groups; Group 1 (remifentanyl-bandaged, n=40), Group 2 (lidocaine-bandaged, n=40) and Group 3 (remifentanyl non-bandaged, $\mathrm{n}=40$ ). Mean arterial pressure and pulse rate were recorded before induction, 1 minute after induction and after intubation. An independent anesthetist blind to groups assessed and recorded Verbal Rating Scale.

Results: There were no significant differences between groups regarding demographic variables. Cardiovascular hemodynamics regarding mean arterial pressure and pulse did not change significantly between groups before and after induction and after intubation. Pain scores were comparable between groups.

Conclusion: Remifentanyl can be used either with venous occlusion or as intravenous bolus to prevent rocuronium induced pain with no significant difference and it is as effective as lidocaine.

Key words: Lidocaine, pain, remifentanyl, rocuroniu

From: ${ }^{1}$ Regional Training and Research Hospital, Department of Anesthesiology and Intensive Care, Erzurum, Turkey, ${ }^{2}$ Ataturk University, Faculty of Medicine, Department of Anesthesiology and Intensive Care, Erzurum, Turkey.

Correspondence: Dr Z Arslan, Department of Anesthesiology and Intensive Care Regional Training and Research Hospital, 25240, Erzurum, Turkey. Fax: + 9044223255 55, e-mail:zakir-arslan@ hotmail.com 


\section{INTRODUCTION}

Rocuronium bromide is an aminosteroidal neuromuscular blocker and causes injection pain during anesthesia induction in 95 to $100 \%$ of patients (1-4). Rocuronium bromide can cause severe burning pain on hand and/or arm especially if intravenous catheters are displaced. In some cases, it may cause bronchospasm $(2,5)$. The mechanism through which pain is generated is still unknown but it is generally accepted that this phenomenon is caused by activation of poly modal nociceptors that leads to the release of endogenous mediators such as kinin, histamine and bradikinin and these mediate the pain response $(2,6,7)$. There are several agents (including the use of local anesthetic drugs, thiopental, opioids, ondansetrone, magnesium, ketamine, antihistamines and ketorolac) and methods (dilution of rocuronium solution, slow injection rate and local warming) for alleviating this discomfort $(1,4,5,7-11)$. Many studies showed that lidocaine, remifentanyl and bandage methods are effective in alleviating rocuronium injection pain $(2-4,11-13)$.

In this prospective randomized, double blinded study, we discussed which of the following methods were better in preventing or alleviating the rocuronium-induced withdrawal movements in patients with general anesthesia: 1) intravenous remifentanyl + local bandage, 2) intravenous lidocaine + local bandage, and 3) just intravenous remifentanyl. We also examined the effects of remifentanyl pretreatment on cardiovascular reflexes such as arterial tension and heart rate following endotracheal intubation procedure. 


\section{METHODS}

Design: After approval from our hospital's Ethical Commitee (Erzurum Regional Training and Research Hospital; Order No: 07, date: 10.04.2014) informed consents were obtained from all patients included. Patients older than 17 years old who has not received premedication, no history of allergy to opioids or local anesthetics, with American Society of Anesthesiologists (ASA) I-II physical status, no use of analgesics, elective surgery and general anesthesia were included. A total of 120 patients who underwent different elective surgery types such as cholecystectomy, thyroidectomy, septorhinoplasty, laminectomy and mastectomy that require endotracheal intubation and muscle relaxation were included the study.

Patients were randomly distributed to 3 groups; Group 1 (remifentanyl-bandaged, $n=40$ ), Group 2 (lidocaine-bandaged, $\mathrm{n}=40$ ) and Group 3 (remifentanyl non-bandaged, $\mathrm{n}=40$ ). Patients were not informed about whether these agents would cause pain. Anesthesiologist who applied agents and assessed pain scores did not know which agent was being used. A physician was responsible for preparing agents into syringes. Just numbers were written on these syringes.

Exclusion criteria: Patients receiving premedication drugs, with ASA III-IV physical status, that needs emergency procedures, that have allergic history for opioids and local anesthetics, patients who received sedative and analgesic medication in the last 24 hours, in whom placing intravenous catheter was difficult, patients with thin dorsal veins, with a history of hypertension, ischemic heart disease, severe bradycardia (heart rate $<45$ beats/min), history of chronic pain and neuromuscular diseases, and finally patients who could not give informed consent. 
Interventions: Patients were admitted to operating room without any premedication and $20 \mathrm{G}$ intravenous cannula was placed on dorsal side of their hands. All patients received $3 \mathrm{ml} / \mathrm{kg}$ of saline infusion. Noninvasive monitorization, electrocardiography, noninvasive blood pressure and pulse oximetry was applied. Mean arterial pressure and pulse rate were recorded before induction, 1 minute after induction and after intubation (just after cuff was inflated). Oxygen support was delivered via a face mask if it was required $(\mathrm{Spo} 2<95 \%)$. All drug solutions were prepared with normal saline (remifentanyl $50 \mu \mathrm{g} / 4 \mathrm{ml}$ and lidocaine $40 \mathrm{mg} / 4 \mathrm{ml}$ ). In Groups 1 and 2, pneumatic tourniquets were applied $8 \mathrm{~cm}$ above intravenous cannula and inflated to $50 \mathrm{mmHg}$. Remifentanyl $(50 \mu \mathrm{g} / 5 \mathrm{ml})$ (Ultiva $5 \mathrm{mg}$, GlaxoSmithKline, Finland) was administered intravenously to the patients in Group 1 (Remifentanyl, $\mathrm{n}=40$ ), $40 \mathrm{mg} / 5 \mathrm{ml}$ lidocaine $\mathrm{HCl}$ (2\% Aritmal, $5 \mathrm{ml}$, Osel, Turkey) to the Group 2 (Lidocaine, $\mathrm{n}=40$ ) and $50 \mu \mathrm{g}$ of remifentanyl without pneumatic tourniquet administered intravenously to Group 3 (Remifentanyl, $\mathrm{n}=40$ ). One minute after administration of drugs (tourniquet was deflated in Group 1 and 2), patients in all three groups received $0.6 \mathrm{mg} / \mathrm{kg}$ of rocuronium bromide (Myocron $50 \mathrm{mg} / 5 \mathrm{ml}$, Vem, Turkey) at room temperature prepared as $10 \mathrm{mg} / \mathrm{ml}$ given in 5 seconds. An independent anesthetist blind to groups assessed and recorded VRS ((Verbal Rating Scale; graded as 0-3 in accordance with the scale advocated by Mc Crirrick and Hunter) (14). Zero showed no pain and a pain score of 3 showed severe pain. Immediately afterwards the assessment of rocuronium injection pain; propofol $(2,5 \mathrm{mg} / \mathrm{kg})$ administered intravenously (in 10 seconds) to patients in all groups (to patients in Group 3 fentanyl $1 \mu \mathrm{g} / \mathrm{kg}$ was administered intravenously along with propofol as analgesic). All patients were intubated 120 seconds after rocuronium injection (provided that they were ventilated through mask with 4 lt/min of $\% 100$ oxygen). After intubation, all patients received same anesthesia protocol.

Statistical analysis: Data were expressed as mean \pm standard deviation in continuous variables and percentage (number) in categorical variables. One way Analysis of variance test 
or Kruskal-Wallis test were used to evaluate the difference between three groups for continuous variables. Chi-square test was used to evaluate the difference between three groups for categorical variables. A $\mathrm{P}$ value less than 0.05 was considered statistically significant. Statistical analyses were performed using SPSS software (SPSS 20.0 inc., Chicago, IL, USA).

\section{RESULTS}

There were no significant differences between groups regarding demographic variables (age, weight, gender and ASA physical status) (Table 1). Cardiovascular hemodynamics regarding mean arterial pressure and pulse did not change significantly between groups before and after induction and after intubation (Table 2). In Group 1, fourteen patients (35\%) experienced pain; $20 \%$ of these ( 8 patients) were mild, $12.5 \%$ moderate (5 patients) and only $2.5 \%$ severe (1 patient). In Group 3, 30\% of patients experienced pain; $17.5 \%$ mild (7 patients), 10\% moderate (4 patients), $2.5 \%$ severe pain (1 patient) (Table3). Pain scores were comparable between groups.

\section{DISCUSSION}

This study shows a small bolus dose of remifentanyl is as effective as lidocaine for alleviating rocuronium injection pain and it is a practical method for daily anesthesia practice. As far as we know, our study may be the first that analyzes remifentanil as a possible pretreatment drug of rocuronium induced pain on injection by both using the venous occlusion technique and direct intravenous injection. 
Rocuronium is commonly used for endotracheal intubation, preventing muscle fasciculations caused by lysthenon and muscle relaxation necessary for surgery. General agreement is that rocuronium is not suitable for awake patients (5). Hand and arm movements or general body movements can be seen due to rocuronium injection during anesthesia induction even after patient is unconscious $(6,7)$. Additionally it can cause extra stress for the patient. Because of this discomfort that the patient faces with, we did not form a placebo group in our study.

The mechanism of rocuronium induced pain is still not clear but it can be due to release of endogenous mediators such as histamine and bradykinin, activation of nociceptors by low $\mathrm{pH}$ or unphysiological osmolality of solutions and allogenic effect of aminosteroidal neuromuscular blocking drugs $(6,7,13,15)$.

There are many factors that affect frequency and intensity of rocuronium injection pain such as region where the injection was applied, size of the vein, injection speed, concentration of drug, temperature of solution and gender of the patient (15-17).

Several methods were recommended to alleviate rocuronium induced pain, however there is no single successful method and success rate varies greatly $(2,3,7,18)$. Use of lidocaine for this indication is highly accepted. Cheong et al. found incidence of rocuronium induced pain as $77 \%$ and they reduced it by $70 \%$ with the use of $30 \mathrm{mg}$ lidocaine, recommending use of a larger dose (12). However Abu-Hallaweh et al. emphasized that duration of tourniquet was more important than dose of lidocain (2). We used $40 \mathrm{mg}$ of lidocaine with a tourniquet time of 1 minute and $62.5 \%$ of our patients did not experienced pain. Moreover besides lidocaine, opioids are used frequently for this indication $(2,3)$. Remifentanyl is a synthetic opioid and metabolized by esterase. When compared with other opioids, it has more rapid onset, much shorter action period, shorter half-life and more powerful effect. Because of these characteristics, it provides more stable hemodynamic parameters during anesthesia induction than other opioids like alfentanyl, sufentanyl and fentanyl. These characteristics have recently 
made remifentanil an ideal coping drug against noxious stimuli (4). Because remifentanyl is more potent and in physiological $\mathrm{pH}(\mathrm{pKa}=8.4)$ about $90 \%$ of it is non-ionized, it has more rapid onset of action (2). In most of the studies, remifentanyl is used for preventing rocuronium induced pain together with either venous occlusion or intravenous rapid administration. We studied both methods and compared this with lidocaine. Abu-Hallaweh et al. proposed that when remifentanyl is administered at a dose of $1 \mu \mathrm{g} / \mathrm{kg}$ along with venous occlusion method, it is more effective on rocuronium induced pain than fentanyl and lidocaine (2). In a randomised double-blind study by Choi et al.; remifentanyl was administered as 0.5 and $1 \mu \mathrm{g} / \mathrm{kg}$ intravenous doses. Thiopental was given 30 seconds later as a dose of induction and following 20 seconds, rocuronium was applied. In both groups injection pain was prevented successfully (97\% and 100\%). However, this success in preventing injection pain can be attributed to thiopental (4). In our study, $65 \%$ of patients in bandaged-remifentanyl group and $70 \%$ of patients in non-bandaged remifentanyl group did not experience injection pain; and only 1 patient in each group had severe pain. Apart from injection pain, we also compared hemodynamic parameters before and after anesthesia induction and after intubation among groups $(8,19)$. It is well known that remifentanyl provides stable hemodynamic parameters in perioperative period $(4,8,19-21)$. Choi et al. showed stability in hemodynamic parameters can be obtained successfully by use of two different doses of remifentanyl $(0.5$ and $1 \mu \mathrm{g} / \mathrm{kg}$ ) compared to saline (4). Not occurrence of difference between groups regarding to hemodynamic parameters such as mean arterial pressure and heart rate may result from use of fentanyl $1 \mu \mathrm{g} / \mathrm{kg}$ as analgesic in lidocaine group.

In conclusion we suggest that remifentanyl can be used either with venous occlusion or as intravenous bolus to prevent rocuronium induced pain with no significant difference and it is as effective as lidocaine. Additionally, it can be easily used in routine anesthesia practice and 
it provides stable hemodynamic parameters. However a higher dose of remifentanyl can be studied for a better efficacy. 


\section{REFERENCES}

1. Reddy MS, Chen FG, Ng HP. Effect of ondansetron pretreatment on pain after rocuronium and propofol injection: a randomised, double-blind controlled comparison with lidocaine. Anaesthesia 2001;56(9):902-5.

2. Abu-Halaweh SA, Aloweidi AK, Qudaisat IY, Al-Hussami MO, Atyat BS, AlMustafa M, et al. Comparison of three methods of preventing rocuronium induced pain on injection using venous occlusion technique: a randomized prospective double blind controlled study. Middle East J Anesthesiol 2013;22(1):87-92.

3. Singh M, Chauhan H, Rath GP, Prabhakar H, Bithal PK, Dash HH. Effect of narcotic pretreatment on pain after rocuronium injection: a randomized, double-blind controlled comparison with lidocaine. J Anesth 2007;21(4):510-2.

4. Choi BI, Choi SH, Shin YS, Lee SJ, Yoon KB, Shin SK, et al. Remifentanil prevents withdrawal movements caused by intravenous injection of rocuronium. Yonsei Med J 2008;49(2):211-6.

5. Mahajan C, Rath GP, Bithal PK, Prabhakar H, Yadav R, Dube SK. Local warming at injection site helps alleviate pain after rocuronium administration. $\mathbf{J}$ Anesth 2010;24(6):845-8.

6. Borgeat A, Kwiatkowski D. Spontaneous movements associated with rocuronium: is pain on injection the cause? Br J Anaesth 1997;79(3):382-3.

7. Lockey D, Coleman P. Pain during injection of rocuronium bromide. Anaesthesia $1995 ; 50(5): 474$.

8. Shin YH, Choi SJ, Jeong HY, Kim MH. Evaluation of dose effects of magnesium sulfate on rocuronium injection pain and hemodynamic changes by laryngoscopy and endotracheal intubation. Korean J Anesthesiol 2011;60(5):329-33. 
9. Dalgleish DJ. Drugs which cause pain on intravenous injection. Anaesthesia 2000;55(8):828-9.

10. Lee HJ, Han SJ, Kim H, Lee IO, Kong MH, Kim NS, et al. Antihistamine pretreatment to reduce incidence of withdrawal movement after rocuronium injection. J Korean Med Sci 2009;24(5):879-82.

11. Zhang Y, Xiang Y, Liu J. Prevention of pain on injection of rocuronium: a comparison of lidocaine with different doses of parecoxib. J Clin Anesth 2012;24(6):456-9.

12. Cheong KF, Wong WH. Pain on injection of rocuronium: influence of two doses of lidocaine pretreatment. Br J Anaesth 2000;84(1):106-7.

13. Memis D, Turan A, Karamanlioglu B, Sut N, Pamukcu Z. The prevention of pain from injection of rocuronium by ondansetron, lidocaine, tramadol, and fentanyl. Anesth Analg 2002;94(6):1517-20.

14. McCrirrick A, Hunter S. Pain on injection of propofol: the effect of injectate temperature. Anaesthesia 1990;45(6):443-4.

15. Klement W, Arndt JO. Pain on i.v. injection of some anaesthetic agents is evoked by the unphysiological osmolality or $\mathrm{pH}$ of their formulations. $\mathrm{Br} \mathrm{J}$ Anaesth 1991;66(2):189-95.

16. Shin YH, Kim CS, Lee JH, Sim WS, Ko JS, Cho HS, et al. Dilution and slow injection reduces the incidence of rocuronium-induced withdrawal movements in children. Korean J Anesthesiol 2011;61(6):465-9.

17. Mencke T, Schreiber JU, Knoll H, Stracke C, Kleinschmidt S, Rensing H, et al. Women report more pain on injection of a precurarization dose of rocuronium: a randomized, prospective, placebo-controlled trial. Acta Anaesthesiol Scand 2004;48(10):1245-8. 
18. Park JT, Choi JC, Yoo YS, Lee YB, Kim SY, Lim HK. The effect of pretreatment with thiopental on reducing pain induced by rocuronium injection. Yonsei Med J 2005;46(6):765-8.

19. Casati A, Fanelli G, Albertin A, Deni F, Danelli G, Grifoni F, et al. Small doses of remifentanil or sufentanil for blunting cardiovascular changes induced by tracheal intubation: a double-blind comparison. Eur J Anaesthesiol 2001;18(2):108-12.

20. Vickovic S, Pjevic M, Stanisavljevic S. Remifentanil and conventional laryngoscopy and tracheal intubation. Med Pregl 2007;60(11-12):593-7.

21. Mireskandari SM, Abulahrar N, Darabi ME, Rahimi I, Haji-Mohamadi F, Movafegh A. Comparison of the effect of fentanyl, sufentanil, alfentanil and remifentanil on cardiovascular response to tracheal intubation in children. Iran $\mathbf{J}$ Pediatr $2011 ; 21(2): 173-80$ 
Table 1: Demographic data of patients

\begin{tabular}{llllll}
\hline & Group & 1 & Group & 2 & Group \\
& $(\mathrm{n}=40)$ & $(\mathrm{n}=40)$ & 3 & P value \\
& $36.8 \pm 15.6$ & $36.0 \pm 16.0$ & $39.9 \pm 14.0$ & 0.493 \\
\hline Age; years & $72.2 \pm 11.2$ & $72.6 \pm 14.9$ & $76.7 \pm 14.6$ & 0.268 \\
Weight; kg & $57.5(23)$ & $55.0(22)$ & $47.5(19)$ & 0.653 \\
Gender, male; \% (n) & $82.5(33)$ & $82.5(33)$ & $82.5(33)$ & 1.000 \\
ASA I physical; \% (n) & & & &
\end{tabular}

Group 1: Remifentanyl with tourniquet; Group 2: Lidocaine with tourniquet; Group 3:

Remifentanyl without tourniquet; ASA: American Society of Anesthesiologists

Table 2: Vital signs of patients measured pre and postinduction and postintubation

\begin{tabular}{|c|c|c|c|c|}
\hline & $\begin{array}{l}\text { Group } \\
(n=40)\end{array}$ & $\begin{array}{l}\text { Group } \\
(n=40)\end{array}$ & $\begin{array}{l}\text { Group } 3 \\
(n=40)\end{array}$ & $P$ value \\
\hline Preinduction MAP; mmHg & $101.7 \pm 13.4$ & $101.9 \pm 15.0$ & $103.3 \pm 18.2$ & 0.891 \\
\hline Preinduction pulse; rate/min & $95.9 \pm 17.4$ & $91.4 \pm 16.9$ & $88.4 \pm 14.1$ & 0.118 \\
\hline Postinduction MAP; mmHg & $76.0 \pm 10.8$ & $82.7 \pm 13.3$ & $79.4 \pm 17.1$ & 0.104 \\
\hline Postinduction pulse; rate/min & $81.4 \pm 14.0$ & $84.4 \pm 17.8$ & $81.5 \pm 15.8$ & 0.624 \\
\hline Postintubation MAP; mmHg & $102.7 \pm 15.1$ & $94.9 \pm 17.9$ & $97.8 \pm 22.3$ & 0.171 \\
\hline Postintubation pulse; rate/min & $92.4 \pm 12.3$ & $97.2 \pm 16.4$ & $91.4 \pm 15.2$ & 0.174 \\
\hline
\end{tabular}


Table 3: Frequency and characteristics of pain on injection of rocuronium among groups

\begin{tabular}{lllll}
\hline Pain score & Group 1 $(\mathrm{n}=40) ; \%$ & Group 2 $(\mathrm{n}=40)) ; \%$ & Group 3 $(\mathrm{n}=40)) ; \%$ & P value \\
& $(\mathrm{n})$ & $(\mathrm{n})$ & $(\mathrm{n})$ & \\
\hline None & $65.0(26)$ & $62.5(25)$ & $70.0(28)$ & \\
Mild & $20.0(8)$ & $20.0(8)$ & $17.5(7)$ & 0.712 \\
Moderate & $12.5(5)$ & $7.5(3)$ & $10.0(4)$ & \\
Severe & $2.5(1)$ & $10.0(4)$ & $2.5(1)$ & \\
\hline
\end{tabular}

